\title{
Simulation analysis of biomass pyrolysis based on the improved CPD model with chain reaction dynamics
}

\author{
Bin Chen ${ }^{1}$, Mengxue Yuan ${ }^{2}$, Sha Wang ${ }^{2}$, Jun Shen ${ }^{2}$, and Yun Guo ${ }^{2}$ \\ ${ }^{1}$ Shanghai University of Engineering Science \\ ${ }^{2}$ Affiliation not available
}

December 4, 2021

\begin{abstract}
The complex composition and molecular structure of biomass lead to more complex and diversified chemical reactions in the pyrolysis. According to the structural characteristics of the reactants, this paper simplifies the pyrolysis process and extends the research focus from the micro-molecular elementary reactions to the macro reaction kinetics. The wheat straw is chosen as the investigated biomass, and the promoted chemical percolation devolatilization (CPD) with modified pseudo-grid and chain reaction kinetics (CRK) pyrolysis models were constructed for predicting the pyrolysis characteristics. Compared with the experimental results, the prediction errors of char, oil and gas production are in a reasonable range of $<10 \%$. Moreover, the reliability of the model is verified by comparing with the experimental thermogravimetric curve, which shows that the model could well predict the mass loss, product distribution and component characteristics, and provides a reasonable prediction for the pyrolysis of biomass.
\end{abstract}

\section{Hosted file}

Manuscript.docx available at https://authorea.com/users/449515/articles/548029-simulationanalysis-of-biomass-pyrolysis-based-on-the-improved-cpd-model-with-chain-reactiondynamics 